\section{Solodovnik G.,} Kovalenko $\mathbf{K}$.

\title{
DEVELOPMENT OF AN AUTOMATED INDUSTRIAL DYNAMICS SYSTEM
}

The object of research is the process of determining the main indicators of the functioning of a manufacturing enterprise using the method of system dynamics. Any enterprise for the production and sale of products is a complex socio-economic system that is closely related to the external environment through input and output channels. The external environment determines the conditions for the functioning of the enterprise and can be described by a set of a large number of different parameters, the values of which will dynamically change and are fundamentally indeterminate.

Coordination and control over material and financial flows at a manufacturing enterprise is often a separate problem. The interaction of financial resources and material flows, which are selected by the enterprise as the main ones in accordance with market requirements and the specifics of the activity, must be coordinated accordingly to achieve a more efficient operation of the enterprise. Therefore, the task of the presented study is to develop a model of material and financial flows of a production enterprise with its further software implementation. The purpose of the software implementation is to further conduct experiments with the model to determine the main indicators of the production enterprise, depending on changes in the functioning parameters due to the external environment.

All the variety of modeling methods considered in modeling theory can be conditionally divided into two groups: analytical and simulation modeling. To solve the problem of this study, simulation modeling was used, which provides for the construction of a model with characteristics adequate to the original on the basis of a certain information principle.

In the course of the research, a model of material and financial flows of a production enterprise was built. The mathematical model of flows was developed using the system dynamics method by J. Forrester. An automated system was also developed, which is a software implementation of the proposed model.

The automated system of industrial dynamics of a production enterprise developed in the study will significantly increase the efficiency and scientific validity of decisions regarding the management of material and financial resources.

Keywords: industrial dynamics, material flows, financial flows, automated system, activity diagram.

\section{Introduction}

Today the world practice of making complex management decisions in socio-economic, political, technical and other systems has acquired a fundamentally new methodological and instrumental support. Before being implemented in practice, the solutions must be pre-tested on analogs of real systems, that is, on models. Simultaneously with this trend, there is a rapid development of the information technology industry and the expansion of the role of this industry in the management of social processes. This makes the processes of automation of management functions a catalyst for managerial progress. In this regard, the implementation of the results of decision-making or innovation requires preliminary assessments of the final results using system analysis and simulation.

An enterprise for the production and sale of products is a complex system. From the standpoint of systems analysis, such a system can be reflected by a certain structure (elements and connections between them) and dynamics (changes in the state of the system over time). System dynamics is a simulation approach that, through its methods and tools, allows to understand the structure and dynamics of complex systems. With the help of this approach, it is possible to obtain adequate computer models of complex systems, which are subsequently used to design a more efficient organization of the system control process [1,2].
The stated facts determine the relevance of the development of a model of material and financial flows of a production enterprise in the notation of the methodology of system dynamics by J. Forrester. The task of automating this model for conducting experiments and determining the best strategies for managing the material and financial resources of the enterprise is also relevant.

\section{The object of research and its technological audit}

The object of research is the process of determining the main indicators of the functioning of a manufacturing enterprise using system dynamics. The subject of this research is object-oriented methods for the development of automated systems.

The main characteristics of effective enterprise management are an extremely high degree of complexity, dynamism and uncertainty. Enterprises must constantly monitor changes in the external and internal environment and effectively respond to them by adjusting the internal organizational and economic structure of enterprise management [3].

The presented study is based on modeling the dynamics of an enterprise, therefore it is necessary to find out the internal and external factors that affect the activities of the organization. 
Any enterprise is an open system, therefore the results of its functioning directly depend on the external environment, namely on the timely supply of resources, energy, personnel, as well as the number of consumers. Environmental factors can be viewed as opportunities or threats to the enterprise, depending on the effectiveness and adaptability of management. Environmental factors are most often classified into the following groups: economic, socio-demographic, technological, competitive, geographic, political. In these work, when constructing models, the factors of the first three groups are mainly taken into account.

The internal environment of an organization is determined by internal factors - situational driving forces within the organization. The main factors in any organization are goals, structure, objectives, technology, people and resources. Modeling production dynamics involves reflecting changes in the main indicators of the amount of resources, finished products and financial assets of the enterprise. The movement of resources in a manufacturing enterprise can be represented as a simplified conceptual diagram (Fig. 1).

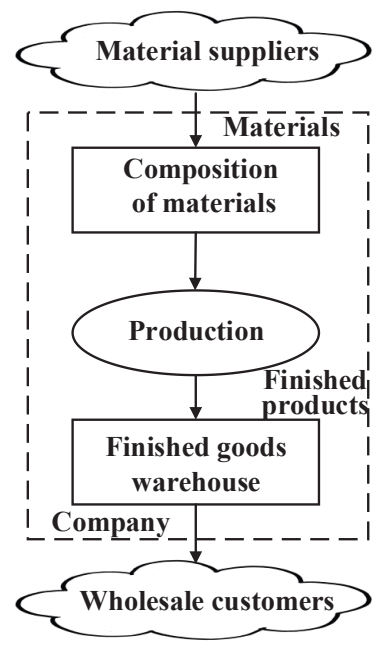

Fig. 1. Simplified conceptual diagram of material flows

To formalize the description of the elements of a complex system, it is necessary to have a mathematical scheme for displaying processes that also takes into account the action of random factors. The process of developing a formalized scheme of the object under study includes several stages:

- structuring the object into separate modules;

- presentation of each module in the form of a finite set of elements (elementary processes);

- displaying the diagram of links of elements in the module;

- selection of mathematical tools for a formalized description of the operation of each element and module as a whole;

- formation of input and output data for each element and module;

- choice of methods for mathematical calculation of elementary processes.

Simulation modeling is a research method in which the system under study is replaced by a model, describes the real system with sufficient accuracy by formalized methods (for example, analytical in the form of mathematical formulas). The model is developed in order to obtain information about the system. Such information can only be obtained by experimenting with a model called imitation. Therefore, for the practical application of the models in the control process, the mathematical description of the model is not enough; its software implementation with an interface that takes into account a specific user-manager is required.

Thus, the problem arises of automating the process of determining the main indicators of the functioning of a production enterprise, depending on the change in the values of the input parameters of external factors of its functioning.

\section{The aim and objectives of research}

The aim of research is to develop an automated system for calculating and visualizing the main indicators of material and financial flows of a production enterprise using system dynamics.

To achieve the aim, it is necessary to solve the following objectives:

1. Build a mathematical model of the movement of material and financial flows of a production enterprise.

2. Determine the goals of developing an automated system for the movement of material and financial flows relative to the user.

3. Development of an automated system for industrial dynamics.

\section{Research of existing solutions of the problem}

As a result of the analysis of existing solutions to the problem, reflected in the sources of the world scientific periodicals, the works $[4,5]$ are highlighted, investigating the issues of increasing the efficiency of the process of managing socio-economic systems, but the solutions they highlight are of a general nature.

Papers $[6,7]$ are devoted to the application of models in the process of controlling complex systems. However, these works do not touch upon the issues of modeling the dynamics of production processes.

Modeling production dynamics is the subject of research in $[1,8]$. The authors of the works aimed to familiarize the public with the scientific principles of the system dynamics method, without taking into account specific examples of its application to simulate specific industrial enterprises.

Some of the analyzed works investigate the issues of modeling the dynamics of material or financial flows of enterprises, but the scope of their application is very narrow or specific. In [9], a dynamic model of material flow is developed in order to coordinate this flow with production processes. The studies highlight the issues of material flow information management for the petrochemical industry, significantly narrowing the scope of their application. Another area of research of models of financial flows is the study of credit funds and portfolios of securities in relation to various socio-economic systems [10]. There are a number of works devoted to modeling financial flows at the industry or country level. So, in [11], a macroeconomic model of the influence of international driving factors on the development of countries is studied. In [12] a model of financial flows is considered, analyzes the influence of the movement of financial resources on the country's economic growth. However, these models can't be applied to study the functioning of an enterprise. The work [13] provides a classification of logistic financial flows, as well as an analysis of their essence, however, the research results have a purely scientific 
direction, which complicates their practical application for solving specific management problems.

From the point of view of practical application in the process of managing a manufacturing enterprise, works [14-16] are interesting. Research in [14] touches upon the issues of automation of modeling material flows by software implementation of a dynamic model based on the concept of Petri nets. The research results are of great scientific and practical interest, but can't be applied by enterprise managers who are not experts in the field of graphs. Studies [15] are devoted to the issues of simulation modeling of the dynamics of complex systems and comprehensively analyze the range of problems that can be solved using this modeling method. Work [16] highlights the possibilities of using the automation of simulation models in the process of managing socio-economic systems. However, the mentioned studies lack examples of building models of specific production systems.

The conclusion from the analysis of literary sources is the need to develop an automated system to determine the main indicators of material and financial flows of a production enterprise using system dynamics.

\section{Methods of research}

A mathematical model of the movement of material and financial flows of a production enterprise was built using the system dynamics of J. Forrester. System dynamics is the modeling and imitation of complex dynamic socioeconomic systems, characterized by branched, in the general case, nonlinear structures - control loops [1, 17].

Forrester's model building methodology is based on common structural elements that are suitable for modeling almost any socio-economic system:

- rates - parameters of streams leaving one integrating

links (levels) and entering others, causing corresponding changes in both groups;

- levels - regulated objects, which formally reflect the variables, are the main indicators of the system's functioning, the parameters of which are obtained by integrating the corresponding characteristics of the flows; - decision functions - a ratio that reflects functional dependencies existing in the system and determines the intensity of input and output flows (there are regulators of a multi-loop control system);

- auxiliary quantities - actively participate in determining the general characteristics;

- parameters - model constants.

Mathematical models are formalized using a system of difference equations defined in terms of discrete times of the same length DT. During the construction of equations, three points in time are considered: $J$ - preliminary, $K-$ current, $L$ - future (Fig. 2).

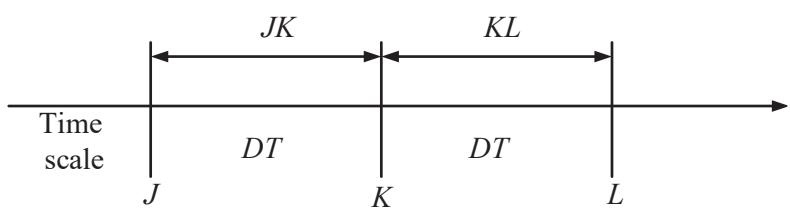

Fig. 2. The principle of organizing system time in Forrester's models

One of the features of Forrester's system dynamics is the ability to graphically describe mathematical models using the corresponding symbols of structural diagrams.
The tool for creating an automated system of industrial dynamics is object-oriented methods of software development $[18,19]$. Before developing a software implementation of the model, a review of existing analogues should be carried out.

Today there are a large number of software tools for building simulation models of business processes. Business Process Simulator is the latest web service for simulating business processes, as well as calculating their cost and analyzing efficiency. The advantages of the service are the availability of a database and free access. The disadvantages are the lack of administration and an insufficiently user-friendly interface. Another analogue of the automated system is the ELMA business process management system. The advantages of this analogue are the presence of a database that allows making queries on many process parameters. The disadvantages are the paid access to the application and the imperfection of the interface. Another software product for modeling business architecture is Business Studio, which has the advantage of having a database. Among the shortcomings of Business Studio are its paid-for, insufficiently intuitive interface and lack of administration.

The main disadvantage of these analogs is the lack of visualization of the results of calculations of changes in the main indicators of material and financial flows of a production enterprise.

\section{Research results}

The development of a mathematical model of the material and financial flows of an enterprise is based on the following hypotheses:

- the enterprise produces one type of product, for the manufacture of which three types of resources are needed; - products are sold in bulk from the production;

- the profit of the enterprise is income from the sale of products after deducting payments for resources for the manufacture of products and the main types of taxes and mandatory payments.

The initial data of the model are: the number of goods in the finished goods warehouse, the optimal order value for each type of resource, the amount of each type of resources in the enterprise's warehouse, the amount of profit.

The main input data of the model is the value of the above variables at the initial moment of time, as well as the price per unit of production, the cost of a unit of each type of resource, the amount of mandatory contributions and taxes.

The period of model analysis, i. e. recalculation of its formulas should be chosen based on the intensity of production and product characteristics.

The diagram of the material flow model in the notation of the system dynamics methodology is shown in Fig. 3.

A graphic element in the form of a cloud reflects the elements of the metasystem that are external to the control object. Here is an explanation of the main variables and parameters of the model, which correspond to the legend on the material flow diagram:

- $I_{j}$ - parameter that determines the amount of costs for storing a unit of resources of each type $j=1 \ldots 3$;

- $Y_{j}$ - parameter that determines the amount of expenses for the supply of a unit of resources of each type; - $M_{j}^{\text {norm }}$ - auxiliary variable, determines the optimal order size for resources of each type;

- $m_{j}^{w}-$ rate of receipt of each type of resource to the manufacturer's warehouse from the supplier's warehouse (after payment for the resource); 
- $M_{j}^{w}-$ level variable, determines the amount of each type of resource in the warehouse of the enterprise; - $m_{j}^{p r}$ - of receipt of each type of resource in production (in accordance with the needs of the production process);

- $\varepsilon_{j}$ - parameter that determines the amount of each type of resource required for the production of one unit of production;

- $\rho_{\max }^{e q}-$ parameter that determines the maximum productivity of equipment for the current number of equipment units at the enterprise;

- $\rho_{\max }^{\text {zoork }}-$ parameter that determines the maximum productivity of workers by the number of workers employed at the enterprise at the moment;

- Pplan - auxiliary variable that determines the total quantity of goods that are planned to be sold at the next planning stage;

- $V$ - level variable, determines the amount of products in production;

- $Z$ - auxiliary variable, determines the quantity of goods ordered by wholesale buyers;

- $O$ - rate of shipment of goods to wholesale buyers; - $\rho^{\text {mat }}-$ auxiliary variable, determines the level of receipt of materials for production;

- $\rho^{\text {norm }}$ - auxiliary variable, determines the normal rate of production;

$-S$ - quantity of goods in the warehouse of the enterprise.
Let's note that the level of the quantity of products in production $V$ is a variable determined using the thirdorder lag equations (Z3). Lags characterize the transformation process, as a result of which, based on the given rate of the input flow $(\rho)$, the rate of the output flow is established. Lag is a specific level, the output of which depends on the content of the level and some constant $\left(\xi^{p r}\right)$ that determines the duration of the lag. The mathematical notation of the third order lag is a system of six equations, three of which are level equations, and three are rates.

The rate of receipt of goods for wholesale buyers is determined by the formula:

$$
O=\frac{Z}{\tau}
$$

where $\tau-t$-class parameter that determines the period between solutions of the equations of the mathematical model of material and financial flows.

Normal production rate:

$$
\rho^{\text {norm }}(t)=\frac{P^{\text {plan }}(t-\tau)-S(t)}{\tau},
$$

where $S(t)$ - amount of goods in the warehouse of the enterprise in the current period of time; $P^{\text {plan }}(t-\tau)$ - total quantity of goods to be sold at the next planning stage.

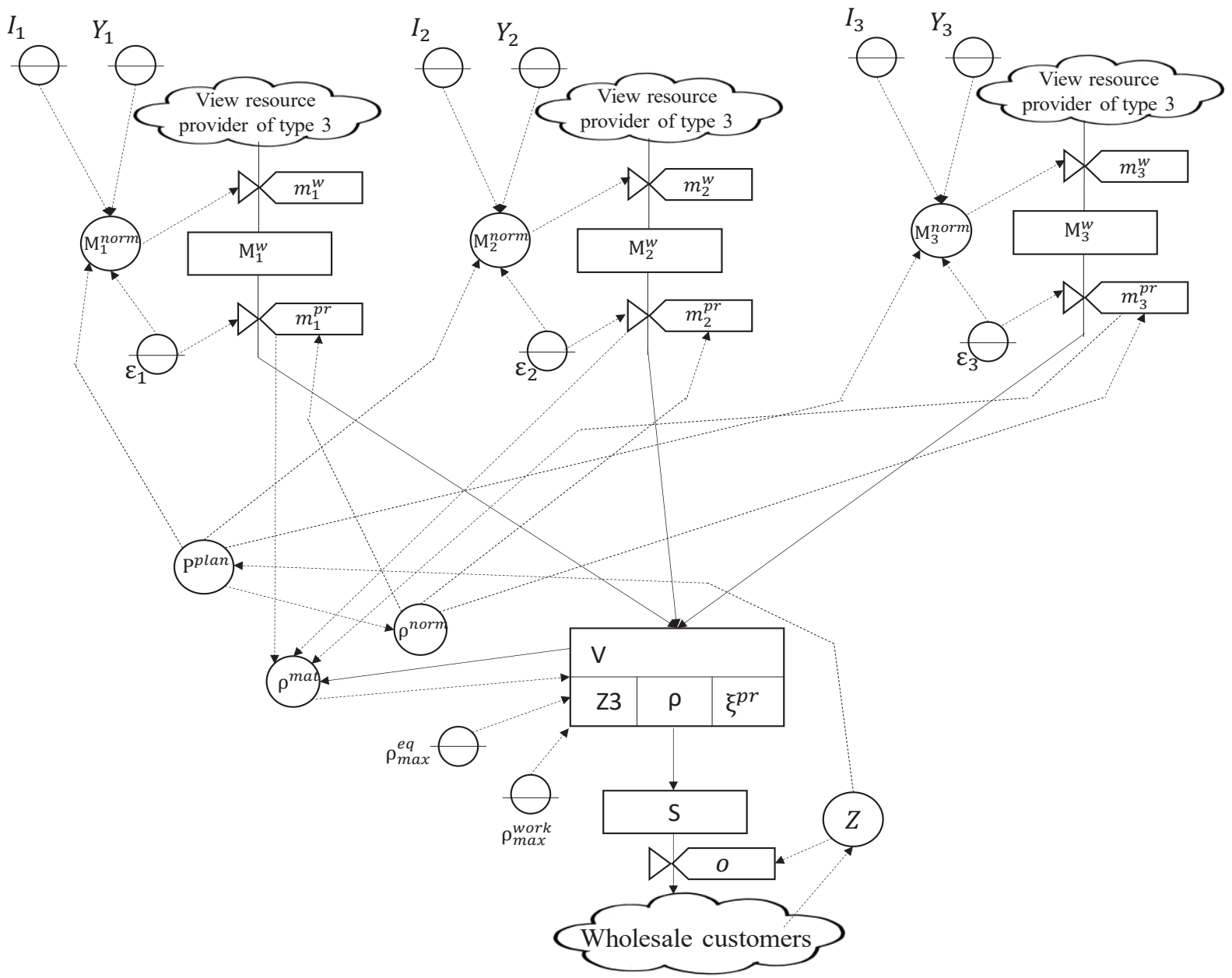

Fig. 3. Diagram of the material flow model 
The optimal order size according to the criterion of minimizing the total costs of storage and repetition of the order is calculated using the Wilson formula [20]. The optimal order size for each type of resources at the current stage of the enterprise's operation:

$$
M_{j}^{\text {norm }}(t)=\sqrt{\frac{2 Y_{j} \rho^{\text {norm }}(t) \varepsilon_{j}(t)}{I_{j}}}
$$

The formula for the quantity of goods in the finished goods warehouse at the current stage is determined by the formula:

$$
S(t)=S(t-\tau)+\tau\left(\rho(t)-o^{\text {whol }}(t)\right)
$$

where $S(t-\tau)$ - the quantity of goods in the finished goods warehouse in the previous period.

The level formula determines the amount of each type of resource in the warehouse of the enterprise, looks like:

$$
\begin{aligned}
& M_{j}^{w}(t)=M_{j}^{w}(t-\tau)+ \\
& +\tau \cdot\left(m_{j}^{w}(t)-m_{j}^{p r}(t)\right),
\end{aligned}
$$

where $M_{j}^{w}(t-\tau)$ - level of the amount of each type of resource in the enterprise's warehouse in the previous period.

Rate of goods receipt to the manufacturer's warehouse from the supplier's warehouse:

$$
m_{j}^{w}=\left\{\begin{array}{l}
\frac{M_{j}^{\text {norm }}}{\tau}, \text { if } M_{j}^{\text {prov }}(t) \geq M_{j}^{\text {norm }}, \\
\frac{M_{j}^{e q}(t)}{\tau}, \text { if } M_{j}^{\text {prov }}(t)<M_{j}^{\text {norm }},
\end{array}\right.
$$

where $M_{j}^{\text {prov }}$ - amount of each type of resource, provided with funds (determined during the experiment with the model of financial flows).

The purpose of modeling financial flows is to determine the amount of profit, that is, the amount of funds that an enterprise can, at its discretion, distribute among its needs, for example, for the purchase of new equipment, advanced training of workers or other measures to improve competitiveness.

When analyzing the economic activity of an enterprise, net profit is defined as gross profit after payment of income tax. In turn, gross profit is equal to the difference between the amount received from the sale of goods and the amount that determines the cost of the sold lot of goods. The costs included in the cost of goods can be represented by the following list:

- payment for raw materials and supplies;

- remuneration of basic workers;

- remuneration of administrative and managerial per-

sonnel and engineering and technical personnel;

- payment of amortization expenses;

- payment for the lease of buildings, production and retail space, equipment;

- payment of commercial expenses [20].

The diagram of the model of financial flows is shown in Fig. 4.

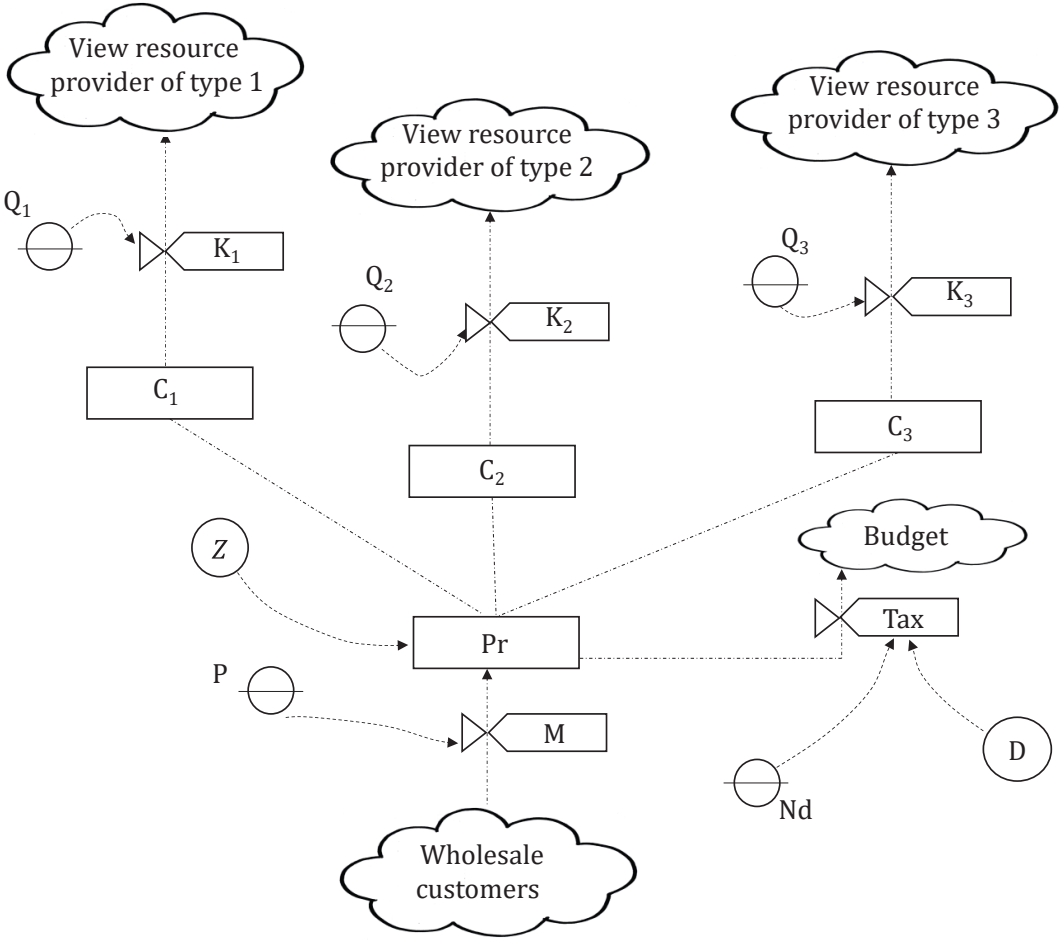

Fig. 4. Scheme of the model of financial flows

Step explanation of the main variables and parameters of the model, which correspond to the legend on the cash flow diagram:

- $Q_{j}$ - parameter that determines the specific cost of resources of each type $j=1 \ldots 3$ per unit of goods;

- $K_{j}$ - rate of receipt of funds to resource suppliers;

- $C_{j}$ - level variable, determines the total amount of funds paid for each type of resource;

- Pr - level variable, determines the profit of the enterprise;

- $M$ - rate of receipt of funds from wholesale buyers;

- Nd - parameter that determines the amount of corporate income tax;

- $D$ - auxiliary variable that determines the income of the enterprise from the sale of products (determined on the basis of experiments with the model of material flows);

- $P$ - parameter that determines the unit price;

- Tax - the rate of mandatory contributions to the budget.

The following formulas should be used to build the model.

1. Profit formula:

$$
\begin{aligned}
& \operatorname{Pr}(t)=\operatorname{Pr}(t-\tau)+D \cdot\left(1-N_{d}\right)- \\
& -Z_{p}-\sum_{i=1}^{n} C_{j}-Z(t) \cdot \sum_{i=1}^{n} I_{j} \cdot \varepsilon_{j},
\end{aligned}
$$

where $\operatorname{Pr}(t-\tau)-$ level of profit of the enterprise in the previous period; $\operatorname{Pr}(t)$ - level of profit of the enterprise in the current period; $Z_{p}$ - parameter of the model, determines the size of the wages of employees; $n$ - number of resource providers $(n=3)$.

2. The formula for the rate of receipt of funds from wholesale buyers:

$$
M(t)=\frac{Z(t) \cdot P}{\tau} .
$$


3. The rate of receipt of funds for suppliers of products is determined by the formula:

$$
K_{j}(t)=\frac{M_{j}^{\text {norm }} \cdot Q_{j}}{\tau},
$$

then the level variable that determines the total amount of funds paid for each type of resource will be determined by the formula:

$$
C_{j}(t)=C_{j}(t-\tau)+K_{j}(t)
$$

During experiments with the model, in addition to the basic initial data describing the influence of the external environment on the operation of enterprises, the user can vary other parameters, for example, the price of products or the productivity of workers.

Automation of the above model will allow the user to assess the functioning of the material and financial components of the enterprise under various scenarios of changes in external and internal factors. The goals of developing an automated system in relation to users are as follows:

- the ability to create and solve the problem of finding the values of the main indicators of the functioning of a manufacturing enterprise;

- the ability to visualize calculations in the form of graphs and diagrams of material and financial flows;

- the ability to save tasks for further editing;

- the ability to administer users.

An automated system can have the following classes of people (organizations or other systems of software devices) interacting with the system that is being developed:

a) a guest who has the ability to: solve the problems of calculating the main indicators of the functioning of a production enterprise using an automated system using a material flow model, register and log in;

b) an authorized user who can: solve the problems of calculating the main indicators of the functioning of a production enterprise using an automated system using a model of material and financial flows, save the creation of a task for further use or editing, view statistics on tasks;

c) an administrator who can: manage task data, manage users.

An activity diagram is built for each class. In Fig. 5, for example, let's give a diagram of the activity of an authorized user.

The automated system database consists of five tables:

1) material model input tables (initial_m);

2) financial model input tables (initial_f);

3) tables of initial data of the material model (output_m);

4) tables of source data of the financial model (output_f);

5) tables of user accounts (user).

When developing an automated system, the following main classes were used:

- class SiteController (class for working with the main page of the site and the contact page);

- abstract class AdminBase (contains general logic for controllers used in the admin panel);

- class User (class for working with users);

- class AdminUserController (manage users in the admin panel);

- class UserController (controller for working with users);

- class CabinetController (controller for working with the user's cabinet);

- class Materials (class for working with material flows);

- class MaterialsController (controller for working with materials flows, containing model calculations);

- class Result materialsController (controller for working with the results page of the material flow model);

- class Finance (class for working with financial flows);

- class FinanceController (controller for working with financial flows, containing model calculations);

- class Result_financeController (controller for working with the results page of the financial flows model).

Working with an automated system begins with the main form (Fig. 6).

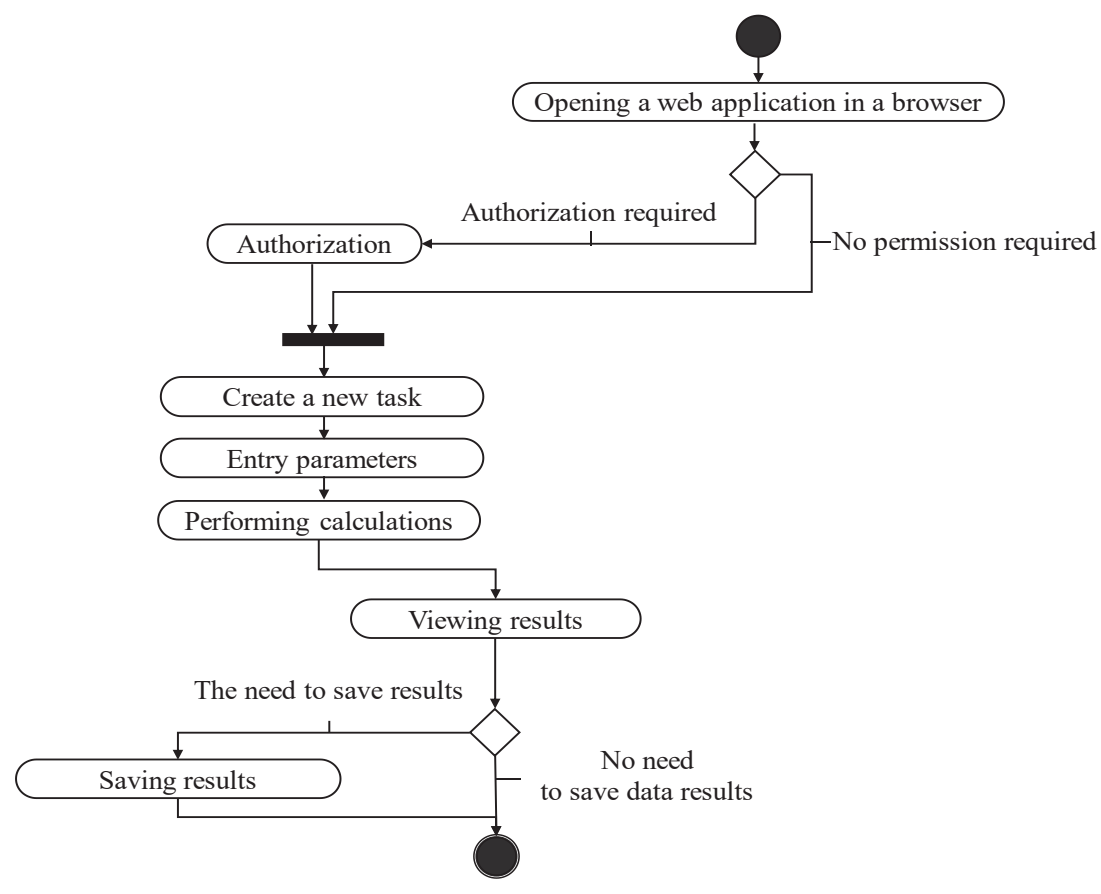

Fig. 5. Activity diagram of an authorized user 


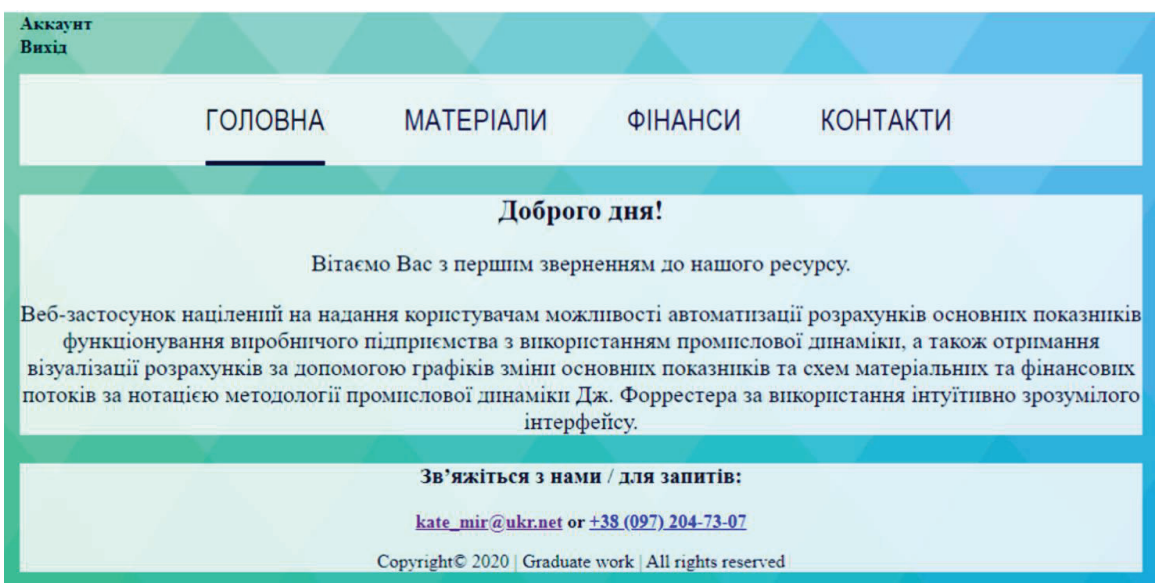

Fig. 6. Screen form of the main page

The Account/Login button allows the user to log in. The Materials menu item displays pages with requests for input data and the results of the system operation after calculations are performed using the material flow model. The Finance menu item works in a similar way regarding the cash flow model. The Contacts menu item provides the user with information about the system developers. The link at the bottom of the screen allows to send a request to the system administrator.

As a result of the simulation experiment, the user is presented with a page containing:

- graphical interpretation of the model of material or financial flows, presented in Fig. 3, 4;

- quantitative values of indicators of the functioning of the enterprise at the end of the planning period with respect to the movement of material flows (optimal order size, normal production rate, etc.) or financial flows (rate of receipt of funds from buyers, etc.);

- tables containing the change in the values of the main indicators during the entire planning period by weeks for the material flow model (the rate of shipment of goods to customers, the number of finished products in the warehouse) or for the material flow model (income, profit);

- graphs of the values of the main indicators of functioning by week for the entire planning period.

In the course of further improvement of the automated system, it is planned to add a menu item Help, which will contain user instructions from the basic principles of working with the system.

\section{SWOT analysis of research results}

Strengths. The developed automated system has the following advantages:

- provides the user with the ability to calculate the main indicators of the movement of material and financial flows under various scenarios of changes in demand and other environmental factors;

- provides a graphical and tabular presentation of the results, as well as a graphical representation of the model; - provides the ability to save and edit the received solutions.

Weaknesses. The weaknesses of the automated system are: - the limited amount of resources involved in the production of goods;
- lack of implementation of modeling of the retail link of trade;

- consolidated accounting of sources of obligatory contributions.

Opportunities. The application of the developed automated system in practice will reduce the time for making management decisions on the production activities of the enterprise and will increase their scientific validity. The automated system provides the user with the ability to visually view the results of the enterprise, depending on changes in the main external and some internal factors of functioning.

Threats. Threats to the operation of the system can manifest themselves due to the interference of viruses, hardware failure, ignorance of users about the subject area of the system, dishonest performance of duties by the administrator. Further improvement of the automated system of industrial dynamics provides for imparting capabilities that can reduce the threats of user ignorance and imperfection of the system administrator.

\section{Conclusions}

1. As a research result, the main parameters of the functioning of the production enterprise were determined. A model of movement of material and financial flows has been built, which reflects the change in the values of these parameters according to possible changes in environmental factors. The model is based on the system dynamics method of J. Forrester. The developed model allows using linear equations to describe the dynamics of material and financial flows of the enterprise, which greatly simplifies its further software implementation. Also, with the help of the developed model, the user gets the opportunity to graphically display the constructed mathematical model, which significantly increases its confidence in the calculations and raises awareness in the processes of movement of material and financial resources.

2. Based on the examination of software products that solve similar problems of supporting management decisions, the goals of developing an automated system for the movement of material and financial flows relative to the user were formulated. These goals are to provide the following opportunities:

- creation and solution of problems of finding the values of the main indicators of the functioning of a production enterprise; 
- obtaining visualization of calculations in the form of graphs and schemes of material and financial flows;

- storage of tasks with their subsequent editing;

- user administration.

The implementation of these goals in the developed automated system is its advantages over the considered analogues.

3. At the last stage of research, an automated system of industrial dynamics was developed. Using object-oriented programming methods, activity diagrams were built for each of the user classes. The class of unauthorized users is highlighted, who are given the opportunity to carry out calculations only by the model of material flows. The class of authorized users is also highlighted, with the capabilities of which calculations are added according to the model of financial flows, saving and editing the results of calculations. A separate class of users is the administrator who has access to view and edit the system user accounts. The constructed activity diagrams ensured further correct development of the functionality of the automated system and writing the program code.

In the course of the research, a database was developed for storing user accounts and the results of calculations for their tasks, as well as classes and controllers for implementing the model and the system interface. Automation of the calculation process based on the created simulation model is implemented in the development environment Visual Studio, PHP programming language for using the hypertext markup language HTML and the CSS page style language.

The implementation of an automated system of industrial dynamics into the enterprise management system will increase its competitiveness due to the efficiency and scientific validity of decisions.

\section{References}

1. Sterman, J. (2000). Business Dynamics: Systems Thinking and Modeling for a Complex World. Boston: Irwin/McGraw-Hill, 982.

2. Rassokha, I. M. (2011). Metodolohiia ta orhanizatsiia naukovykh doslidzhen. Kharkiv: KhNAMH, 76.

3. Miziuk, B. M. (2009). Osnovy stratehichnoho upravlinnia. Lviv: Mahnoliia, 544

4. Negulescu, O., Doval, E. (2014). The Quality of Decision Making Process Related to Organizations' Effectiveness. Procedia Economics and Finance, 15, 858-863. doi: http://doi.org/10.1016/ s2212-5671(14)00548-6

5. Tohidi, H., Jabbari, M. M. (2012). Decision role in management to increase effectiveness of an organization. Procedia Social and Behavioral Sciences, 31, 825-828. doi: http://doi.org/ 10.1016/j.sbspro.2011.12.149

6. Akdere, M. (2011). An analysis of decision-making process in organizations: Implications for quality management and systematic practice. Total Quality Management $\mathcal{E} \mathcal{F}$ Business Excellence, 22 (12), 1317-1330. doi: http://doi.org/10.1080/14783363.2011.625180

7. Bolle-Reddat, B., Dumora, R. (2016). The Role of Models in Management Decision. Modelling in Life Insurance - A Manage- ment Perspective, 7, 130-141. doi: http://doi.org/10.1007/ 978-3-319-29776-7 11

8. Winter, S. G., Kaniovski, Y. M., Dosi, G. (2000). Modeling industrial dynamics with innovative entrants. Structural Change and Economic Dynamics, 11 (3), 255-293. doi: http://doi.org/ 10.1016/s0954-349x(99)00010-7

9. Li, D., Liu, L., Zhu, W., Rong, G. (2008). Material-flow Modeling Technology and Its Application in Manufacturing Execution Systems of Petrochemical Industry. Chinese Journal of Chemical Engineering, 16 (1), 71-78. doi: http://doi.org/10.1016/ s1004-9541(08)60040-3

10. Lim, G. C. (1991). Estimating portfolio models from financial flow data: An analysis of the demand for liabilities, real assets and financial assets by the household sector. Economic Modelling, 8, 219-224. doi: http://doi.org/10.1016/0264-9993(91)90016-h

11. Mody, A., Taylor, M. P., Kim, J. Y. (2001). Modelling fundamentals for forecasting capital flows to emerging markets. International Journal of Finance $\mathcal{E} \mathcal{F}$ Economics, 6 (3), 201-216. doi: http://doi.org/10.1002/ijfe.159

12. Combes, J.-L., Kinda, T., Ouedraogo, R., Plane, P. (2019). Financial flows and economic growth in developing countries. Economic Modelling, 83, 195-209. doi: http://doi.org/10.1016/ j.econmod.2019.02.010

13. Sumets, O. M., Kyzym, M. O., Syromyatnikov, P. S., Kozureva, O. V., Tsvirko, O. O. (2019). Financial flows in logistics systems of production enterprises. Financial and Credit Activity: Problems of Theory and Practice, 3 (30), 165-175. doi: http:// doi.org/10.18371/fcaptp.v3i30.179529

14. Ladiges, J., Fulber, A., Arroyo, E., Fay, A., Haubeck, C., Lamersdorf, W. (2015). Learning material flow models for manufacturing plants from data traces. 2015 IEEE 13th International Conference on Industrial Informatics (INDIN). doi: http://doi.org/ 10.1109/indin.2015.7281750

15. Suprunenko, O. A. (2013). Paradigms of simulation modeling in studying complex parallel systems. Eastern-European Journal of Enterprise Technologies, 5 (4 (65)), 63-67. Available at: http://journals.uran.ua/eejet/article/view/18353

16. Sheshasaayee, A., Bhargavi, K. (2017). A study of automated decision making systems. Research Inventy: International Journal of Engineering And Science, 7, 28-31.

17. Solodovnyk, H. V. (2016). Instrumentalni zasoby modeliuvannia sotsialno-ekonomichnykh system. Kharkiv: Rozhko S. H., 122.

18. Booch, G., Maksimchuk, R. A., Engle, M. W., Young, B. J., Conallen, J., Houston, K. A. (2007). Object-Oriented Analysis and Design with Applications. Addison-Wesley Professional, 720.

19. Rosenberg, D., Scott, K. (2007). Use Case Driven Object Modeling with UML: A Practical Approach. Addison-Wesley Professional, 188. doi: http://doi.org/10.1007/978-1-4302-0369-8

20. Ivanilov, O. S. (2009). Ekonomika pidpryiemstva. Kyiv: Tsentr uchbovoi literatury, 728 .

Solodovnik Ganna, PhD, Associate Professor, Department of Computer Science and Information Technology, Kharkiv National University of Civil Engineering and Architecture, Kharkiv, Ukraine, e-mail: solodovnik@kn-it.info, ORCID: http://orcid.org/0000-00016323-5083

Kovalenko Kateryna, Department of Computer Science and Information Technology, Kharkiv National University of Civil Engineering and Architecture, Kharkiv, Ukraine, e-mail: kate mir@ukr.net, ORCID: http://orcid.org/0000-0003-1260-367X 